\title{
A VUELTAS CON LA REVOLUCIÓN FRANCESA. VIEJOS DEBATES Y NUEVAS PROPUESTAS
}

\section{THINKING ABOUT THE FRENCH REVOLUTION. OLD DEBATES AND NEW PROPOSALS}

\author{
Mercedes Vázquez de Prada \\ Universidad de Navarra
}

Entregado el 4-11-2013 y aceptado el 5-9-2014.

Resumen: Después de dos siglos de debate, la Revolución francesa sigue siendo una de las áreas intelectualmente más creativas y que suscita mayores polémicas. La historia de la Revolución Francesa sigue estando muy viva y proyecta su compleja trayectoria sobre la actualidad como antecedente de conflictos sociopolíticos y desafíos de la democracia. A medio camino entre estructuras, ideas y mentalidades, la historiografía y las investigaciones recientes prosiguen a buen ritmo en medio de un intenso debate. Este artículo repasa la evolución reciente de dichas polémicas historiográficas y algunos de los principales temas y tendencias actuales en la investigación sobre la Revolución. Tras la hegemonía revisionista del bicentenario se constata, sobre todo en Francia, una revitalización de la herencia clásica. La ampliación temática, la complejidad del análisis y una perspectiva global muestran que, lejos de estar superado, el debate historiográfico apunta la necesidad de profundizar en la interpretación de los sistemas interactivos que articulan los engranajes de la Revolución.

Palabras clave: Revolución francesa, historiografía, Terror, bicentenario, postrevisionismo, neojacobinos, Robespierre

\footnotetext{
Abstract: After two centuries of debate, the French Revolution remains one of the most passionately contested and intellectually creative areas of historical enquiry. The history of the French Revolution is still very much alive and projects its complex path up till now as history of sociopolitical conflicts and challenges to democracy. A half way between structures, ideas and mentalities,
} 
historiography and recent investigations continue at a good pace in the middle of an intense debate. This article revises recent approaches in historiography and some of the main topics and current trends in revolutionary research. After revisionist hegemony of the bicentennial, on observe - specially, in France - a revival of the classical paradigm. Thematic broadening, the complexity of analysis and a global perspective show that far from being over, historiographycal debate suggests a necessity to interpret the interactive systems which produced the mechanisms of the Revolution.

Key words: French Revolution, Historiography, Terror, Bicentennial, Postrevisionism, New Jacobinism, Robespierre 


\section{Introducción}

La Revolución francesa es el acontecimiento que abre el mundo contemporáneo. Los revolucionarios franceses no sólo crearon un nuevo modelo de sociedad y de estado, sino que difundieron un modo nuevo de pensar por la mayor parte del mundo. Es por tanto un fenómeno de carácter global. Quizá uno de los hechos que mayor atención haya despertado en la historia. La Revolución francesa ejerce una fascinación enorme, tanto entre los historiadores, como entre los ciudadanos en general, porque revela muchas de las ideologías y convicciones políticas más íntimas. Aparte de monografías de investigación, sirvan como ejemplo, el best seller la Revolución Francesa, publicado por Max Gallo en $2009^{1}$ o la audiencia millonaria que concentró ese mismo año en Gran Bretaña un programa sobre Robespierre y la Revolución emitido por la cadena BBC 2.

Momento fundador de la Francia contemporánea y también de la cultura política moderna, la Revolución ha suscitado intensos debates en el campo de la historiografía. ${ }^{2}$ Pocos temas han sido objeto de mayor polémica y diversidad de planteamientos. Si el bicentenario de la Revolución, en 1989, dejó algo claro es que ésta mantenía intacto su poder de atracción, división y politización. Nada de esto ha cambiado.

En este artículo se recorren algunas de las grandes corrientes de interpretación de la Revolución desde las primeras décadas del siglo XX hasta la actualidad. Se resaltan sobre todo el impulso del bicentenario, el estancamiento de la corriente postrevisionista desde finales de la centuria y los principales temas y debates planteados en los últimos años.

\section{Las grandes controversias del siglo $\mathrm{xx}$ : marxistas versus revisionistas}

La Revolución nunca ha podido evitar las controversias que acompañaron a su nacimiento. Piedra de toque de la modernidad, este acontecimiento presenta, no obstante, dos caras contrapuestas. Símbolo de la li-

\footnotetext{
${ }^{1}$ Révolution française, Tome I: Le Peuple et le Roi (1774-1793) Tome 2: Aux armes, citoyens! (1793-1799) XO, París, 2009.

2 Véase, entre otros, Rebecca Spang, Paradigms and Paranoia, «How Modern is the French Revolution», en American Historical Review, 108, n. ${ }^{\circ}$ 1, febrero 2003, pp. 119-147;

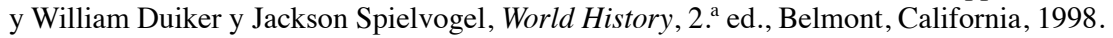


bertad, de la igualdad y de la fraternidad y también sombría imagen del terror paradójicamente aplicado en nombre de aquellas conquistas. La historiografía vuelve una y otra vez sobre ella y la cuestión se politiza hasta tal extremo, que aún en los últimos años los especialistas reconocen la existencia de un apasionado juego de «fútbol político» ${ }^{3}$.

Desde el pasado siglo se han venido enfrentando dos corrientes paralelas: la escuela marxista que hace una lectura social de la revolución (representada por historiadores como Alphonse Aulard - primer titular de la cátedra de historia de la revolución en la Sorbona en 1886-, George Lefebvre, Albert Soboul o Albert Mathiez ${ }^{4}$ ), entendida como revolución burguesa y la escuela revisionista ${ }^{5}$, conservadora y moderada, (cuyos nombres más destacados son François Furet, Denis Richet y Alfred Cobban), centrada sobre todo en el sujeto, y que la considera como un fenómeno principalmente político y cultural ${ }^{6}$. La imagen que se impone sobre el acontecimiento revolucionario está marcada, para los primeros, por una idealización del modelo revolucionario y para los segundos, por el rechazo y abominación de los totalitarismos del siglo XX.

Para la escuela marxista, la Revolución no significó únicamente una lucha política contra la monarquía absoluta hacia un republicanismo democrático, sino un giro más abrupto desde el feudalismo al capitalismo. La Revolución estaría protagonizada por la alianza entre la elite burguesa y las clases populares contra la nobleza terrateniente. La interpretación

${ }^{3}$ David Andress, «The Shifting Landscape of Revolutionary Interpretations: A Death of the Past and a Rebirth of History?» en French Historical Studies, 32, 2009, p. 653.

${ }^{4}$ Véase Aulard, François-Alphonse, The French Revolution, a Political History, 1789 1804, 4 vol. 1910.

Georges Lefebvre, fundador en 1937 del Instituto de Historia de la Revolución Francesa, expuso la versión definitiva de su interpretación marxista de las causas de la Revolución de 1789 en su obra: La Révolution française, publicada en 1930. La edición revisada en 1951 fue traducida al inglés en 1962.

5 El revisionismo histórico se refiere a la reevaluación crítica del conocimiento disponible sobre un evento histórico con nuevos datos o análisis más precisos de los ya conocidos. La década que precede al bicentenario de la Revolución registró una de las grandes polémicas revisionistas de la historia. A partir de esta gran «querelle», ha sido habitual en algunos ámbitos académicos denominar revisionismo a las explicaciones históricas en términos de cultura política, ideología y decisión frente a estructuras sociales y económicas.

${ }^{6}$ Michael Scott Christofferson, «An Antitotalitarian History of the French Revolution: François Furet's Penser la Révolution française in the Intellectual Politics of the Late 1970s» en French Historical Studies, 22, 1999, pp. 557-611. 
de la revolución es esencialmente la de un conflicto de clases en el que se destruye a la nobleza, despierta la clase de los sans-culottes y la burguesía se hace con el control del estado.

En los años posteriores a la Segunda Guerra Mundial y con el apogeo de la escuela de Annales ${ }^{7}$ a fines de los cincuenta, dicha interpretación sería mayoritariamente aceptada, incluso por historiadores sociales que no se consideraban propiamente marxistas. La explicación de la Revolución, entendida así como un proceso social y económico y conocida como «interpretación clásica», dominó claramente hasta mediados de la década de los sesenta ${ }^{8}$.

Con todo, en 1956 surge una primera polémica cuando Jacques Godechot - discípulo de Lefebvre - pasa un año con Robert Palmer en Princeton para preparar un informe sobre el problema del Atlántico en el siglo XVIII para el Congreso Internacional de Ciencias Históricas que tendría lugar en Roma en 1955. Godechot plantea entonces la tesis de una gran revolución atlántica y europea, que relativiza el carácter principal de la revolución francesa. El escándalo que produjo en Francia fue amainando al reconocer Palmer la originalidad de la Revolución francesa en ese proceso atlántico más amplio, en cuanto supone la destrucción total del régimen feudal ${ }^{9}$.

El «gran ataque» a la interpretación social de la revolución se produciría algunos años después, cuando un grupo de historiadores británicos y americanos cuestionaron la existencia de una clara división de clases en la sociedad de la pre-revolución francesa. Alfred Cobban, investigador de la universidad de Londres, puso en duda que la Revolución fuera dirigida por una burguesía en ascenso. En su opinión, fue una revolución de notables y no de burgueses capitalistas. Su tesis principal es que la revolución comienza al menos en 1787, puesto que el reinado de Luis XVI fue un pe-

${ }^{7}$ La escuela de Annales, fundada en la etapa de entreguerras por Lucien Febvre y Marc Bloch, sucede la la escuela metódica de la Revue Historique creada en 1876 por Gabriel Monod. Gracias a su evolución y apertura a las ciencias sociales, esta corriente domina prácticamente toda la historiografía francesa del siglo Xx.

8 Para una versión más amplia desde el punto de vista anglosajón, véase Geoffrey Ellis, «The Marxist interpretation of the French Revolution», en The English Historical Review, vol. 93, n. ${ }^{\circ}$ 367, abril 1978, pp. 353-76; Sanford Elwitt, «Soboul's Marxism», en Proceedings of the Consortium on Revolutionary Europe, XIII, 1984, p. 316-24; Jack Amariglio, Bruce Norton, «Marxist Historians and the Question of Class in the French Revolution», History and Theory, vol. 30, n. ${ }^{\circ} 1$. febrero, 1991, pp. 37-55.

9 The Age of the Democratic Revolution, Princeton, 1959. 
ríodo de reformas que ésta trata de continuar. La idea de una revolución de 1789 burguesa y antifeudal sería una ilusión, pues comienza por una revuelta aristocrática que pretende ganar el poder y es, ante todo, política y no social ${ }^{10}$.

El norteamericano George Taylor aportó en 1966 mucha prueba empírica a las tesis revisionistas de Cobban. Así, defiende que no es posible distinguir entre nobleza y burguesía - tanto desde el punto de vista social como económico - y sugiere también que el origen de la Revolución debe entenderse como una reivindicación del poder político ${ }^{11}$. La cuestión es que las tesis de Cobban y Taylor no acertaron a explicar cuáles fueron realmente las causas de la Revolución y para los especialistas franceses los revisionistas fueron una minoría iconoclasta ${ }^{12}$.

Pero las contradicciones que mostraba la tesis marxista y su incapacidad para pulsar la ideología y las representaciones o el «imaginario» se hacían evidentes para François Furet, cuando publicó - con Denis Richet- en 1965, la Révolution française. Albert Soboul y Claude Mazauric tacharon enseguida la obra de ahistórica y antifrancesa, e incluso reprocharon a Furet su vinculación con la sección IV de l'École Pratique des Hautes Études — creada y financiada en 1947 por la Fundación Rockefeller- y rival de la Sorbona.

El enfrentamiento fue subiendo de tono al atacar Furet violentamente a Soboul en «Le catéchisme révolutionnaire», publicado en 1971 en $A n$ nales ESC ${ }^{13}$, y llegó a su cenit, cuando presenta, en 1978, «Penser la Révolution française ${ }^{14}$. Un conjunto de ensayos con una clara crítica antitotalitaria. El historiador francés abandona su tesis anterior (Ilustración moderada seguida por el Terror) y considera el Terror como algo inseparable de 1789. La línea maestra de la Revolución no era la lucha de clases, sino el deseo de radicalizar la Revolución, que adquiría consistencia a tra-

10 The Social Interpretation of the French Revolution, Cambridge University Press, 1964. Esta obra no fue traducida al francés hasta 1984.

11 Véase «Non Capitalist Wealth and the Origins of the French Revolution», en American Historical Review, 72,2, 1967, pp. 469-496.

${ }^{12}$ Una visión de conjunto sobre esta tesis la ofrece William Doyle en Origins of the French Revolution, Oxford, 1980.

${ }^{13}$ La obra de Soboul Précis d'histoire de la Révolution française, publicada en 1962, era tachada de vulgata populista y leninista. Para una exposición más detallada del enfrentamiento político véase Michael Scott Christofferson, French Intellectuals against the Left: The Antitotalitarian Moment of the 1970s, Berghan Books, 2004.

${ }^{14}$ Paris, Gallimard. 
vés del nuevo vocabulario político de democracia directa, igualitarismo y voluntad general. Una revisión que implicaba sustituir lo social por lo político: de una explicación social con consecuencias políticas a una revolución política con consecuencias sociales. Esta interpretación insiste por ello en la importancia del concepto de cultura política y cuestiona, además, si las consecuencias inmediatas de la Revolución fueron realmente de libertad y de progreso. De hecho, una de las ideas furetianas que se apartan más radicalmente de las tesis marxistas es la del cambio de rumbo de la Revolución desde 1791 y su desviación hacia formas de dictadura que culminaron en el Terror en 1794. Un Terror que entiende como cumbre de la democracia revolucionaria y no como una fase accidental del proceso. De forma provocadora Furet llegó a declarar que la Revolución había terminado ${ }^{15}$. Esta afirmación de que ya no habría necesidad de ningún cambio social radical - en referencia al slogan de los feuillants, una facción conservadora de la burguesía francesa de $1790-$, causó gran escándalo en una historiografía aún dominada por el marxismo.

Pero a fines de los 70, en un ambiente de crisis del comunismo y de denuncia antitotalitaria, la propuesta de rehabilitación de lo político tomará carta de naturaleza. Más que un compromiso con el postestructuralismo, Furet elabora una reconceptualización de la revolución a través de una vuelta a la historiografía del siglo XIX, en especial a las obras de Burke, Tocqueville, Quinet y Cochin. A lo largo de los años 80 Furet, militante comunista hasta el desengaño que le produce la represión del levantamiento húngaro en 1956, se convierte en uno de los intelectuales más influyentes de Francia. La revista Le Nouvel Observateur ${ }^{16}$ le proclama rey de las celebraciones del bicentenario de la Revolución.

\section{El impulso del bicentenario: internacionalización y nuevas perspectivas de la historiografía anglosajona}

Para la política oficial francesa la conmemoración del bicentenario de la Revolución en 1989 tuvo como uno de sus principales propósitos el intento de unir al país y superar las viejas divisiones. El bicentenario sí supuso en cambio un fuerte impulso para la historiografía de la Revolución.

15 Frase que comenta en 1986 en Le Nouvel Observateur, 28-2.

16 Fundada en 1950, se considera la revista de los intelectuales franceses. 
Como demuestran las aportaciones del Congreso Mundial de aquél año sobre La imagen de la Revolución ${ }^{17}$, no se llegó a ningún consenso sobre las causas, desarrollo o implicaciones de la misma. Sin embargo, desde fines de los 80 se celebraron numerosas reuniones científicas y conferencias y los archivos y obras ya publicadas fueron minuciosamente reexaminadas. Una nueva generación de historiadores, principalmente británicos y norteamericanos, abordará con nuevos enfoques, antiguos y nuevos temas.

La insistencia de Furet sobre la importancia del lenguaje, las ideas y los símbolos de los revolucionarios y de sus oponentes, amplía el campo de mira en relación con las nuevas tendencias generales de la historiografía desplegadas desde los años $70^{18}$. El rechazo del determinismo estructural externo y de la noción del discurso político como explicación totalizante se reflejan en la fuerza de la historia cultural y el intento de resolver la cuestión de la génesis de lo social a través de las principales corrientes, revisionistas y posterevisionistas, que abordan el análisis de la Revolución: desde la historia cultural y el análisis del discurso, hasta el rescate de lo social, la vuelta del sujeto y la historia postcolonial y global ${ }^{19}$.

Todas estas corrientes tienen en común, aunque en distinta forma y medida, la introducción del concepto «cultura política». Un concepto, central como se ha visto en la obra de Furet, que trata fundamentalmente de caracterizar el conjunto de lenguajes y prácticas políticas mediante las que se desplegaron las políticas revolucionarias. Algo que se asocia a un nuevo modo de entender la revolución, que cuestiona su naturaleza únicamente social, su carácter de ruptura y su desarrollo progresivo ${ }^{20}$. Los estudios culturales, el post-estructuralismo, la crítica literaria y varias formas de análisis lingüístico resaltan el papel causal y socialmente constitutivo de los procesos culturales y sistemas de significación.

17 Michel Vovelle, L'image de la Révolution francaise: communications présentées lors du congrès mondial pour le Bicentenaire de la Révolution: Sorbonne, Paris, 6-12 juillet 1989, París, Pergamon Press, 1990.

${ }_{18}$ Un recorrido general en Georg Iggers, Historiography in the Twentieth Century, Westleyan University Press, 2005.

19 Álvaro Santana Acuña, «Entre la cultura, el lenguaje, lo «social» y los actores: La nueva historiografía anglófona sobre la Revolución Francesa», en Historia Social, 54, 2006, pp. 157-181.

20 Véase el planteamiento teórico en Jack Goldstone, «Toward a Fourth Generation of Revolutionary Theory», en Annual Review of Political Sciences, 2001, pp. 139-187. 
Otras constantes que se aprecian en las investigaciones de la etapa del postbicentenario son la reevaluación de la relación entre Antiguo Régimen y la Revolución, frente a la tesis clásica de ruptura de 1789, y la inclusión del concepto de espacio público de Habermas. El filósofo alemán considera que la transición a la etapa moderna se carateriza por una reestructuración de la vida pública. Una esfera pública que define como una comunidad virtual o imaginaria que no existe necesariamente en un espacio identificable. En esta forma ideal, la esfera pública está constituida por gente privada que se reúne como pública y articula a través del diálogo, opiniones y actitudes que guían los asuntos de estado ${ }^{21}$.

\section{Historia cultural de la Revolución}

Este enfoque, intensamente marcado por la antropología cultural y la crítica literaria, ha ejercido una poderosa influencia sobre el debate historiográfico de las últimas décadas. Busca un registro analítico más empático con las contingencias de la percepción individual, el lenguaje, el imaginario y la experiencia del «día a día ${ }^{22}$.

Lynn Hunt publicó en 1984 la importante obra Politics, Culture and Class in the French Revolution ${ }^{23}$. Frente al análisis de Furet, la historiadora norteamericana examina no solo los efectos del lenguaje sobre la política, sino las cuestiones más profundas que relacionan las transformaciones políticas y las estructuras mentales internas de ciertos grupos sociales. Hunt expone las prácticas simbólicas, la cohesión retórica y la mobilización política de las clases bajas como evidencia para explicar el descubrimiento del potencial de la acción política para transformar la sociedad, moldeando el carácter, la cultura y las relaciones sociales. Un descubrimiento de la política como potente agente del cambio que deja abierto a distintas conclusiones ${ }^{24}$.

En The Family Romance of the French Revolution Hunt sigue profundizando en la cultura política y analiza los símbolos, rituales y lenguajes

21 Strukturwandel der Öfentlichkeit, Berlin, Luchterhand, 1962.

22 Lynn Hunt (ed.), The New Cultural History, Berkeley, 1989 y Peter Burke, What is Cultural History? Cambridge University Press, 2004.

23 Berkeley, University of California Press, 1984.

24 Véase la crítica de la historiadora norteamericana a Furet en History and Theory, 20, 3, 1981, pp. 313-323. 
que la crearon y transmitieron a la acción revolucionaria. Su obra es un ensayo de historia cultural como relectura de la Revolución a partir de la noción freudiana de «novela familiar» ${ }^{25}$. En este caso, la autora utiliza los conceptos freudianos sobre la dinámica familiar para explicar las tensiones del pensamiento jacobino y la nueva política en las esferas pública y privada. Trata de demostrar con ello cómo las nociones de familia y política estuvieron estrechamente unidas durante la revolución.

David Bell es un autor que relaciona la historia cultural con los conceptos y el lenguaje en la constitución de los procesos históricos. En The Cult of the Nation in France: Inventing Nationalism, 1680-180026 examina el discurso político francés durante la centuria que precede a la Revolución y la formación paulatina de una nueva idea de Francia, que encontraría su expresión más radical a partir de 1789. Bell destaca el poder simbólico de conceptos como «nación» y «patria», que eran empleados como organizadores de la cultura política francesa. Aludirían a una fuerte unión política entre ciudadanos y así, en 1789 los Estados Generales se constituirían en Asamblea Nacional, proclamando que la soberanía residía en la nación. En síntesis, se concluye que la revolución no crea el nacionalismo, sino que culmina una larga evolución histórica.

Sarah Maza realiza otra contribución importante a la historia de la Revolución desde el ángulo cultural. En su ensayo sobre el mito de la burguesía francesa ${ }^{27}$ reconoce que los líderes políticos de la revolución pueden considerarse sociológicamente como burgueses, pero no actuaron como una clase específica. Convencidos por los valores de su época, rechazaron las divisiones sociales como algo artificial y universalizaron la ciudadanía. Las reformas económicas que promocionaron en 1789 buscaban la properidad económica, pero no necesariamente para crear una clase capitalista. La pretendida burguesía revolucionaria, tampoco tendría - al menos en los primeros años - un lenguaje o una ideología que justificara un liderazgo de la clase media. La no identificación de los movimientos políticos franceses con una clase burguesa permite a Maza a plantear la cuestión de la relación entre las instituciones francesas y el grupo social que supuestamente las dominaba durante esa etapa.

25 The Family Romance of the French Revolution, Berkeley, Routledge, 1995.

26 Cambridge, Ma., Harvard University Press, 2001.

27 The Myth of the French Bourgeoisie: An Essay on the Social Imaginary, 1750-1850, Harvard University Press, 2003. 
En Making Democracy in the French Revolution ${ }^{28}$, James Livesey rechaza el planteamiento de Furet sobre el carácter negativo de la política revolucionaria y defiende la creación del modelo de democracia europea. Contextualizando prácticas sociales con ideales políticos, explica cómo en 1795-99 nace un republicanismo comercial que promueve un igualitarismo en sus ideas sobre el desarrollo de la economía, la reforma educativa, etc. Un nuevo republicanismo democrático que estaría en la base de los procesos de modernización en los siglos XIX y XX.

\section{La Revolución Francesa y la historia de género}

La historia de género sobre la revolución ha estado dominada sobre todo por historiadoras culturales. Estos estudios abordan diversas temáticas que profundizan sobre el papel de la mujer en la revolución; las razones que producen el efecto asimétrico sobre los derechos de hombres y mujeres ante el doble modelo excluyente de nación y familia (que las considera sujeto de un tratamiento político particular) y la necesidad de reelaborar conceptos como el de clase social etc. En cuanto al impacto positivo o negativo de la Revolución sobre las mujeres, las posturas difieren.

Joan Landes desafía el análisis de Habermas sobre la esfera pública ante el problemático carácter de la exclusión deliberada de la mujer de la esfera pública burguesa ${ }^{29}$. La revolución relega a la mujer al hogar y recrea una esfera pública burguesa esencialmente masculina y sexista. La adopción formal de unos derechos universales silencia a las mujeres en la vida pública al destacar las concepciones burguesas de la virtud doméstica. Dena Goodman ${ }^{30}$ observa la Ilustración en una comunidad del discurso conocida como la república de las letras, en la que los salones gobernados por mujeres diseñaban el proyecto ilustrado de cambiar los modos de pensar. La autora aporta una nueva explicación sobre la intervención de las mujeres en la Ilustración y demuestra que en la república de las letras hombres y mujeres jugaron un papel complementario, pero desigual.

A estas interpretaciones se oponen otras que afirman el impacto positivo de la revolución sobre las mujeres y que han prevalecido en los úl-

\footnotetext{
28 Cambridge, Harvard University Press, 2001.

29 Joan Landes, Visionalizing the Nation, Cornell University Press, 2001.

30 The Republic of Letters, Cornell University Press, 1994.
} 
timos años. En esta línea se posiciona, por ejemplo, Carla Hesse, en The Other Enlightenment: How French Women Became Modern ${ }^{31}$. Trata de dar una visión positiva del legado revolucionario recogiendo rasgos alternativos del discurso ilustrado que ella denomina «la otra Ilustación». Ésta estaría formada por mujeres que defendían su autonomía moral a pesar de la subordinación política y legal existente. Hesse documenta una participación sorprendentemente activa de las mujeres en la esfera pública moderna a través de las publicaciones de la década de 1790. Unas publicaciones que demuestran su contribución a la la historia de las nuevas ideas y la formación de una nueva sensibilidad.

\section{El giro lingüístico: la revolución discursiva}

El análisis del discurso aporta una interpretación de la cultura política basada en una concepción del lenguaje, no como medio de comunicación, sino como matriz significativa de la realidad. ${ }^{32}$ Así, según este giro lingüístico, los objetos históricos se generan en estrecha relación con el discurso que les otorga significado y no tienen por tanto una existencia independiente del mismo. El lenguaje no solo describe sino que actúa ${ }^{33}$. Keith M. Baker, uno de los principales seguidores de Furet, aplica de forma nítida el giro lingüístico en su investigación. Para este historiador, la cultura política es el conjunto de discursos o prácticas simbólicas mediante las que los individuos o grupos articulan, negocian e imponen las demandas que se hacen entre ellos y al conjunto ${ }^{34}$. En ese contexto explora el lado del «lenguaje» de los juegos de lenguaje (es decir, las formas en que lo social podría ser visto como constituido o reconstituido mediante el discurso). La tesis principal de Baker es que la Revolución parte de un nuevo concepto de la política que hunde sus raíces en la segunda mitad del siglo XVIII. Considera que la creación de un lenguaje revolucionario fue un prerrequisito vital para la revolución y niega que existan realidades so-

\footnotetext{
31 Princeton University Press, 2001.

32 Ernst Breisach, On the Future of History, Chicago, University of Chicago Press, 2003.

33 Véase Elisabeth Clark, History, Theory, Text: Historians and the Linguistic Turn, Harvard University Press, 2004-

34 Véase su artículo «El concepto de cultura política», en Ayer, 62, 2006, 2, pp. 89110.
} 
ciales carentes de significado simbólico. En síntesis, poder político y lenguaje estarían tan estrechamente Unidos, que la revolución se trataría en esencia de una revolución lingüística ${ }^{35}$.

Otras interpretaciones en la línea del análisis del lenguaje defienden una relación mayor con las estructuras socioeconómicas y culturales. Así, Sophia Rosenfeld ${ }^{36}$ considera que la revolución puede entenderse como una lucha por la autoridad sobre las palabras y los signos, dada la influencia de los ilustrados que instituyó en la práctica revolucionaria la relación entre lenguaje y poder político.

La teoría del discurso ha sido muy criticada por diversos historiadores, como Robert Darnton, que considera que - al menos tal como lo entienden Furet o Baker - no da lugar para la contingencia y el proceso revolucionario mismo; no profundiza suficientemente en la historia del significado y no afronta la cuestión del paso de las ideas a la acción ${ }^{37}$.

\section{Postrevisionismo liberal: la vuelta de «lo social»}

El énfasis en el discurso y el giro cultural producen un alejamiento del contenido social de la historia y de las bases materiales de la vida social. Algunos autores utilizan el término postrevisionista para denominar a otra nueva tendencia que plantea rehabilitar la historia social, aunque sin obviar las aportaciones de la historia cultural ${ }^{38}$. Este enfoque, que recoge la tradición democrática liberal, puede seguirse, con distintas propuestas, en historiadores como David Garrioch, John Markoff, David Andress o Susan

35 Inventing the French Revolution: Essays on French Political Culture in the Eighteenth Century, Cambridge University Press, 1991, recoge su obra publicada en los diez años anteriores. Obras más recientes en esa línea son «Political Languages of the French Revolution», en Mark Goldie y Robert Wokler (eds.), The Cambridge History of Eighteenth-Century Political Thought, Cambridge, Cambridge University Press, 2006, pp. 626-59 y «The Idea of a Declaration of Rights,» en Dale Van Kley (ed.), The French Idea of Freedom: Origins of the Declaration of the Rights of Man and of the Citizen, Stanford, California, Stanford University Press, 1994, pp. 154-196.

${ }_{36}$ A Revolution in Language, Stanford, Stanford University Press, 2001.

37 The Forbidden Best-sellers of Pre-Revolutionary France, New York, 1995.

38 Véanse las reflexiones teóricas para una reformulación de los social que incluya las aportaciones del giro linguiístico en William Sewell, Jr., «Para una reformulación de lo social», en Ayer, 62, 2006, 2, pp. 51-72 y Victoria Bonnell y Lynn Hunt (eds.), Beyond the Cultural Turn: New Directions in the Study of Society and Culture, Berkeley- Londres, California Press, 1999 sobre las limitaciones del análisis cultural. 
Desan. Tratan de mostrar que la Revolución no fue un fracaso, que la ascendente burguesía no habría iniciado la Revolución, pero que los revolucionarios desmontaron con éxito el Antiguo Régimen y modernizaron la sociedad que dará el paso a un siglo liberal. Frente a las razones sociales y políticas a que apelaban marxistas y revisionistas como causa del inicio de la revolución, estos historiadores se centran en los ideales y las esperanzas que los actores de la Revolución depositaron en la vida política desde sus diversos ámbitos culturales. En cuanto a la violencia colectiva, creen que en muchos casos fue premeditada y necesaria para establecer un estado liberal ${ }^{39}$.

El historiador australiano David Garrioch argumenta en The Formation of the Parisian Bourgeoisie, 1690-183040, la formación y desarrollo de la burguesía y su relación con la política. Concluye que fue la revolución la que jugó un papel estelar en la creación de una identidad de clase burguesa. No obstante y aunque señala la complejidad de los hechos, le falta explicación sobre la conexión de las relaciones que señala ${ }^{41}$.

En el ámbito americano, Suzanne Desan analiza la transformación de las relaciones sociales durante la revolución a través de la noción de familia. Su obra desafía la interpretación de Furet de que la revolución cayó rápidamente en intereses igualitarios que llevaron directamente al Terror. Desan cree por el contrario que los revolucionarios iniciaron un individualismo radical en lo concerniente a la familia. Un aspecto central para el proyecto de cambio del siglo XVIII. Frente a la postura monárquica y patriarcal del Antiguo Régimen, el nuevo sería democrático e igualitario en las interacciones familiares. Muestra cómo las leyes y políticas producen una revolución en los hogares y la familia se convierte en arena política, un terreno práctico para crear la república ${ }^{42}$.

Otro historiador de lo social, John Markoff ${ }^{43}$, analiza la revolución en el ámbito campesino. Alejado también de la interpretación revisionista,

39 Véase Gary Kates, The French Revolution. Recent Debates and New Controversies, New York, Routledge, 1998.

40 David Garrioch, The Formation of the Parisian Bourgeoisie, 1690-1830, Cambridge, Mass., 1996.

41 Jack R. Censer, «Social Twists and Linguistic Turns: Revolutionary Historiography a Decade after the Bicentennial», en French Historical Studies, vol. 22, n. ${ }^{\circ}$ 1, 1999, pp. 162 y ss.

42 The Family on Trial in Revolutionary France, Los Angeles, University of California Press, 2004.

43 The Abolition of Feudalism: Peasants, Lords, and Legislators in the French Revolution, Penns. University Press, 1996. 
entiende la revolución campesina como emancipatoria e igualitaria. En este sentido, la violencia rural no habría sido irracional, sino una vía para acabar con el poder despótico de los terratenientes.

\section{El retorno del sujeto}

De nuevo como crítica del revisionismo se hace una historia cuyo eje principal es el sujeto. Un giro que trata de rehabilitar a los actores y sus prácticas ${ }^{44}$.Timothy Tackett, en Becoming a Revolutionary, ofrece un ejemplo de esta tendencia. Su ambicioso libro sobre los diputados de la Asamblea Nacional y el nacimiento de una cultura revolucionaria, aunque utiliza técnicas de la historia cultural, contesta la tesis revisionista de que la cultura política y la práctica prerrevolucionaria de los diputados estuvieran impregnadas de los valores de la Ilustración. Mantiene, por el contrario, que éstos eran hombres pragmáticos y con experiencia en la vida política municipal y regional del Antiguo Régimen. Demuestra cómo las reacciones ante las contingencias políticas y las interacciones sociales que experimentan les convierten en revolucionarios. Tackett contradice también la tesis revisionista sobre la violencia revolucionaria. Ésta sería resultado de un complejo proceso de mutación en las convicciones de las elites, la contrarrevolución, el vacio institucional, la presión de las clases populares y la emergencia de una cultura del pánico y de la sospecha ${ }^{45}$. Keith Baker ha criticado a Tackett por tratar al proceso revolucionario como una dinámica psicosociológica que casi pasa por alto los argumentos políticos expuestos por los revolucionarios y las acciones políticas a las que dieron lugar ${ }^{46}$.

Centrado en el evento y el imprevisible resultado sobre las prácticas del sujeto, Michael Fitzsimmons -en The Night the Old Regime Ended: August 4, 1789, and the French Revolution ${ }^{47}$ - estudia la psicología colectiva del momento y concluye que las renuncias de los diputados a sus privilegios tradicionales en la noche del 4 de agosto marcan todo lo que la

${ }^{44}$ Una reflexión teórica puede verse en Gabrielle Spiegel, «La historia de la práctica: nuevas tendencias en historia tras el giro lingüístico», Ayer, 62, 2006, 2, pp. 19-50.

45 Becoming a Revolutionary. The Deputies of the French National Assembly and the Emergence of a Revolutionary Culture (1789-1790), Princeton University Press, 1997.

46 Véase Baker, «El concepto... en Ayer 2006, p. 102-3.

47 Pennsylvania University Press, 2003. 
Asamblea Constituyente realiza en los dos años siguientes y entraña consecuencias sociales para toda la nación francesa.

\section{Experiencias y emociones}

El retorno del sujeto aborda también experiencias y emociones. La intención de explicar cómo ciertas ideas y discursos adquieren significado para los individuos ha derivado hacia la psicología y más específicamente a las respuestas emocionales colectivas que se concretan en la acción política y social ${ }^{48}$. William Reddy plantea la tesis de que la Revolución no puede entenderse sin una adecuada teoría de las emociones. En The Navigation of Feeling, Reddy realiza un estudio interdisciplinario (incluye aspectos psicológicos, antropológicos, históricos y filosóficos) que abre una nueva interpretación sobre el sentimentalismo del siglo XVIII y la república jacobina. La conclusión del autor es que la caída de Robespierre sirvió para cuestionar el papel de las emociones en la política y para terminar con el sentimentalismo e inaugurar el régimen liberal y romántico de las emociones que distingue claramente entre razón y emoción ${ }^{49}$.

La fragmentación del campo de estudio que se observa en esta etapa de la historiografía desde fines de siglo ha convertido a la Revolución en un lugar de interacciones complejas y, en ocasiones, contradictorias. Y es que cuanto más se ha investigado, más difícil es integrar ese conocimiento en las categorías y teorías existentes. Lynn Hunt, indudablemente una de las voces más autorizadas en este debate, planteaba ante ese aparente callejón sin salida, la necesidad de encontrar un nuevo paradigma, no solo para entender la Revolución francesa, sino para las humanidades en general ${ }^{50}$. Hunt invoca en un breve ensayo sobre la experiencia de la

48 Desde el punto de vista teórico critica la noción de racionalidad comunicativa de Habermas. El planteamiento concreto de Reddy puede verse en «Against Constructionism: The Historical Ethnography of Emotions», en Current Anthropology, 1997, 38, pp. 327351. Un estudio sobre las nuevas propuestas y la relación entre historia, psicología y política en: Cristian Tileagă y Jovan Byford (eds.), Psychology and History: Interdisciplinary Explorations, Cambridge Univrsity Press, 2014.

49 William Reddy, The Navigation of Feeling: A Framework for the History of Emotions, Cambridge, 2001.

50 Hunt, «The Experience of Revolution», en French Historical Studies, 32, 4, 2009 , pp. 671-678, p. 671. David Bell, «A la recherche d'un nouveau paradigme?», en H-France Salon, volume 1, Issue 1, n. $^{\circ} 1$, pp. 1-6, p. 1. 
revolución, una reconceptualización de la experiencia individual basada en las nuevas perspectivas que ofrecen las neurociencias y en un nuevo enfoque sobre las formas no verbales de la comunicación, como la cultura visual $^{51}$. En concreto, la historiadora norteamericana propone un relegamiento de los análisis discursivos y volver a retomar la «disciplinariedad» (una vuelta a las certezas y a la autonomía de lo humano como agente histórico). Esta postura de Hunt, que cambia sus posiciones anteriores ${ }^{52}$, ha sido criticada por historiadores que consideran que la experiencia y las emociones, de acuerdo con la rápida evolución de la ciencia actual, constituyen una categoría difícilmente objetivable en el análisis histórico ${ }^{53}$.

En Experiencing the French Revolution ${ }^{54}$, un conjunto de autores exploran diversos temas de la revolución que tocan las «experiencias» (defensa, colaboración, trauma o miedo ante el terror, etc.). El editor de la obra, David Andress, defiende en la introducción que no puede haber un modelo para explicar las experiencias. Piensa que la teoría de Reddy no es adecuada, pues recoge solo lo que la gente dice que siente y reclama la legitimidad con la que cada historiador se puede adentrar en distintos «jardines históricos ${ }^{55}$.

\section{Estudios postcoloniales}

El postrevisionismo colonial comparte, al menos desde finales de los 80 , la idea de que el proceso de modernización en la Francia revolucionaria no puede entenderse sin la integración de la cuestión colonial como parte fundamental del desarrollo de ese proceso, no solo fuera de Europa, sino en la propia Francia ${ }^{56}$. Autores como Patrick Geggus, Laurent Dubois

51 Véase «The Experience of Revolution», French Historical Studies, 2009, 32, 4, pp. 671-67.

52 Sobre esta postura de Hunt véase la discusión en Rebecca Spang, Self, Field, Myth: What We Will Have Been, en H-France Salon, vol 1, 1, n. ${ }^{\circ} 3,2009$, p- 29.

53 Por ejemplo, Sophia Rosenfeld, «Thinking about Feeling», en French Historical Studies, 32,4, 2009, p. 704.

54 Oxford, Voltaire Foundation, 2013.

55 Para una fundamentación conceptual de la influencia de las emociones en el cambio histórico véase J. Moscoso, Pain: A Cultural History, Basingstoke, Palgrave-Macmillan, 2012.

56 Véase Gurminder K. Bhambra, Rethinking Modernity: Postcolonialism and the Sociological Imagination, Basingstoke, Palgrave-Macmillan, 2007. 
o Jeremy Popkin, han centrado su interés en el Caribe y en cómo participaron las antiguas colonias esclavistas en la Revolución: sus grupos culturales, discursos y prácticas ${ }^{57}$. Obras como A Colony of Citizens: Revolution and Slave Emancipation in the French Caribbean, 1787-1804 o You Are All Free: The Haitian Revolution and the Abolition of Slavery no consideran las sublevaciones de los esclavos en la década de los 1790 como una mera explosión frente a la opresión o como eco de la revolución europea. Las revueltas tendrían su origen en un complejo proceso en el que los esclavos acogen las ideas de Europa sobre derechos y libertad y las combinan con las ideas y prácticas caribeñas y africanas para crear algo enteramente nuevo. Con todo, las tensiones entre los contextos locales, regionales y atlánticos de la revolución en el Caribe francés siguen siendo en gran parte una incógnita ${ }^{58}$.

\section{Del «giro haitiano»al «giro global»}

El giro global en los estudios franceses ha obligado a reexaminar la literatura, la lengua, la cultura y la historia de Francia a través de una nueva perspectiva descentralizada y multicéntrica. Autores como el postcolonialista británico Peter Hulme han destacado que la tradición cultural europea, lejos de ser autogenerada es producto de un intrincado curso, muy poco reconocido, de relación con el mundo no europeo ${ }^{59}$. Este nuevo giro historiográfico reclama la atención sobre el impacto constitutivo de las historias globales sobre las locales y más específicamente, una vuelta crítica a las relaciones entre metrópoli y colonia, raza y nación.

Desde la conmemoración - en 2004- del bicentenatio de la Revolución haitiana, nuevos estudios plantean una reconsideración de la revolución de Haití como radicalización de la Revolución Francesa y sus im-

57 David P. Geggus, Haitian Revolutionary Studies, Indiana University Press, 2002; David Geggus, (ed.), The Impact of the Haitian Revolution in the Atlantic World, Charleston, University of South Carolina Press, 2002; Laurent Dubois, A Colony of Citizens: Revolution and Slave Emancipation in the French Caribbean, 1787-1804, Chapel Hill, University of North Carolina Press, 2004; Jeremy Popkin, You Are All Free: The Haitian Revolution and the Abolition of Slavery, Cambridge University Press, 2010. 80 .

58 Véase la reflexión y sus profundas implicaciones en Álvaro Santana, op. cit. pp.179-

59 Subversive Archipelagos: Colonial Discourse and the Break-up of Continental Theory, Disposito 14, 1989, n. 36-8. 
plicaciones democráticas. Se destaca que la formación de una república independiente en la que queda abolida la esclavitud desafía aspectos claves de la Revolución francesa. Un aspecto crucial para restaurar su importancia en la historia global. Historiadores como Laurent Dubois, John Garrigus o Jeremy Popkin consideran la esclavitud como un fenómeno de la historia de los imperios que no puede ser estudiado sin tener en cuenta las interconexiones con la Ilustración, el colonialismo y la práctica judicial colonial en lo referente a la abolición de la esclavitud en la temprana república ${ }^{60}$. Al situar la independencia de Haití en el contexto mucho más amplio de la revolución atlántica del siglo XVIII, que incluye al Atlántico no británico, los historiadores plantean la necesidad de conceptualizar el carácter híbrido de la modernidad postcolonial. Dubois, por ejemplo, demuestra en Avengers of the New World cómo los acontecimientos en los Estados Unidos, Francia, España, Gran Bretaña y Cuba ayudan a conformar el mapa político de la revolución de Haití y cómo la revolución transforma las historias de esas regiones interrelacionadas ${ }^{61}$.

La dimensión transnacional de la Revolución ha sido una cuestión escasamente tratada hasta fechas recientes. En The Global Ramifications of the French Revolution ${ }^{62}$, varios autores se interesaron por su impacto en el Caribe, América y Europa o el África subsahariana para forjar sus propias tradiciones revolucionarias y plantearon nuevas cuestiones sobre el proceso recíproco de construcción del sentido de la revolución entre Francia y el exterior. Bailey Stone - en Reinterpreting the French Revolution: A Global-Historical Perspective - incide en la interacción de las presiones internacionales y la política doméstica de los líderes nacionales que pretenden modernizar las instituciones francesas ${ }^{63}$. Christhopher A. Bayly, en The Birth of the Modern World, 1780-1914: Global Connections and Comparisons ${ }^{64}$, mantiene una tesis más exterior en la que la Revolución habría sido solo una dimensión de la crisis internacional creada por el desajuste entre las necesidades militares y los recursos financieros

60 Véase Anja Bandau, «Transatlantic Representations of the Revolution in SaintDomingue at the End of the Eighteenth Century and The Haitian Turn» en Jana Gohrisch y Ellen Grünkemeier (eds.), Postcolonial Studies Across the Disciplines, Amsterdam-New York, Ansel, 2013, pp. 185-192.

${ }^{61}$ Laurent Dubois, Avengers of the New World: The Story of the Haitian Revolution, Cambridge, Harvard University Press, 2005.

62 Joseph Klaits y Michael Haltzel (eds.), Woodrow Wilson Center Press, 1994.

${ }_{63}$ Cambridge University Press, 2002.

64 Malden, Mass., Blackwell, 2004. 
de los estados. Pero es en los últimos años cuando diversos estudios han abierto nuevas perspectivas al poner el acento sobre las interconexiones globales de la Revolución.

La monografía, The French Revolution in Global Perspective, editada por Suzanne Desan y Lynn Hunt ${ }^{65}$ formula nuevos retos importantes en la línea del «giro global.» Lynn Hunt critica el argumento exterior de Christopher Bayly e insiste - recogiendo la nueva sensibilidad hacia la cuestión colonial que aporta el giro haitiano - en la interacción de las fuerzas locales, nacionales y globales. Se trata por tanto de analizar las repercusiones de los acontecimientos de cualquier parte del mundo, especialmente de las colonias francesas sobre la revolución en la metrópli. Así, por ejemplo, Popkin defiende que las colonias y especialmente Santo Domingo (se refiere a los derechos coloniales y la esclavitud) fueron una presencia permanente en cada fase de la Revolución francesa ${ }^{66}$. Como destacan las editoras de este conjunto de ensayos, el giro global abre nuevos horizontes en los estudios revolucionarios. Evidentemente, la cuestión plantea muchísimos interrogantes y más allá de lo colonial, la vuelta bastante más matizada a «las revoluciones atlánticas». Si ya en los años sesenta, Robert Palmer destacaba que la era de las revoluciones no fueron únicamente levantamientos franceses o europeos, nuevas historias demuestran cómo los conflictos revolucionarios afectan también a sociedades muy alejadas del mundo del Atlántico Norte ${ }^{67}$. En particular se empieza a desentrañar el cómo en la primitiva globalización, las relaciones con los pueblos indígenas y la cuestión esclavista han contribuido a la concepción revolucionaria del comercio, los derechos humanos, el universalismo y la regeneración.

Las editoras aseguran que el análisis global permitirá enlazar factores socioeconómicos con los políticos y culturales. Un enfoque que tendería puentes entre los dos modelos historiográficos que se bifurcan desde

65 Suzanne Desan, Lynn Hunt y William Max Nelson (eds.), The French Revolution in Global Perspective, Cornell University Press, New York, 2013.

66 Jeremy Popkin, «Saint-Domingue», p. 21. El estudio de la política de los años 80 muestra que la Sociedad de Amigos de los Negros se convierte en el primer club revolucionario y sirve de modelo de la política revolucionaria. En segundo lugar, recalca que los agitadores antiesclavistas ayudan a crear el lenguaje de los derechos naturales ya antes de la Revolución.

67 Véase una aportación reciente en el contexto general Atlántico, en David Armitage y Sanjay Subrahmanyam (eds.), The Age of Revolutions in Global Context, c. 1760-1840, London, Palgrave-Macmillan, 2010. 
el bicentenario. Pero como han señalado historiadores como David Bell ${ }^{68}$, si la perspectiva global ayuda a entender el amplio contexto en el que el proceso revolucionario pudo comenzar, no lo hace a la hora de desentrañar el propio proceso. Queda por tanto abierta la gran pregunta de si la Revolución es un espectacular ejemplo de la crisis global de los imperios o, como hasta ahora planteaba la mayor parte de la historiografía «internalista», una convulsión única con consecuencias globales. Bell ha recordado también que los grandes acontecimientos han tenido lugar muchas veces en espacios muy reducidos. ${ }^{69}$

\section{Tendencias recientes en la historiografía francesa de la revolución}

Desde los años 80, la fuerza del revisionismo y el regreso de la corriente contrarrevolucionaria señalan una larga etapa de eclipse para la escuela marxista. La polémica en el Hexágono adquiere en los años del bicentenario una forma triangular. Pierre Chaunu, François Furet y Michel Vovelle sucesor - desde 1980 - de Soboul en la cátedra de la Sorbona, representan los tres ejes sobre los que gira el debate sobre la Revolución: Contrarrevolución, liberalismo conservador y neojacobinismo $^{70}$.

La hegemonía conservadora se mantiene pujante hasta fines de siglo, pero a patir de entonces - y espoleada también por la radicalización del discurso contrarrevolucionario- se observa una revitalización de la herencia clásica.

En la senda abierta por Furet, historiadores franceses han realizado significativas aportaciones desde la línea de la historia cultural, estudios de género etc., incorporando también las corrientes de la historiografía, ya enunciadas, que lideran los anglosajones.

Destacamos algunas obras pioneras en historia cultural y las aportaciones que han supuesto una contribución importante al conocimiento de la revolución desde el ámbito regional. Mona Ozouf publica ya en 1976,

68 «Questioning the Global Turn»: The Case of The French Revolution», en French Historical Studies, 37, 1, 2014, pp. 1-24.

69 Véase el artículo «This Is What Happens When Historians Overuse the Idea of the Network», en New Republic, oct.25, 2013.

${ }^{70} \mathrm{La}$ dureza y politización de los debates puede seguirse en Steven L. Kaplan, Adieu Revolution, París, Fayard, 1993. 
La Fête révolutionnaire, 1789-179971, un libro que abre camino sobre la importancia del simbolismo de la iconografía revolucionaria. La colaboradora de Furet muestra que el sistema de festivales no es marginal al proceso revolucionario, sino un espejo en el que se refleja la revolución y la forma en que se quiere educar en los nuevos valores basados en la familia, la nación y la humanidad de un mundo liberal y secular moderno.

Roger Chartier analiza los orígenes culturales de la revolución como una relectura del siglo XVIII, que tiene también el valor de dar a conocer las aportaciones de historiadores culturales anglófonos poco conocidas entonces en Francia. Partiendo de la obra de Mornet $^{72}$ - publicada originalmente en 1933 - sobre los orígenes intelectuales de la revolución, Chartier amplía con elementos culturales una interpretación de lo social que sitúa el proceso revolucionario en el largo plazo de la etapa de las Luces. Para Chartier no se puede sostener que las prácticas fluyan mecánicamente de las ideas. Es por el contrario una relación ambivalente, compleja y contradictoria entre ambas la que constituiría los orígenes culturales de la Revolución. El mundo de las ideas hay que vincularlo por tanto con las condiciones sociales y materiales que presiden las innovaciones conceptuales ${ }^{73}$.

Dominique Godineau escribe en 1988 una de las primeras obras feministas sobre las mujeres de París. Un minucioso estudio sobre la situación social de las mujeres del pueblo, sus prácticas políticas y las relaciones masculino/femeninas en el movimiento revolucionario entre 1789 y 1795 . Godineau examina cómo las mujeres revolucionarias reclaman su puesto y sus derechos ciudadanos no reconocidos. Destaca el activismo político y sus motivaciones, así como las equívocas respuestas que reciben. Godineau concluye que ni la legislación revolucionaria ni la propia revolución pueden caracterizarse de forma simplista como antifeministas. El activismo de las mujeres y su represión serían más bien parte de la relación fluctuante entre las circunstancias políticas y las ideas acerca del género en dicha etapa ${ }^{74}$.

${ }^{71}$ París, Gallimard. Traducido al inglés en 1988 como Festivals and the French Revolution, Harvard University Press.

72 Daniel Mornet, Les origines intellectuelles de la Révolution française (1715-1787), Lyon. La Manufacture, reeditado en 1989.

${ }^{73}$ Les origines culturelles de la Révolution française, París, Ed. Seuil, 1990.

${ }^{74}$ Citoyennes tricoteuses: les femmes du peuple à Paris pendant la Révolution française, Paris, Perrin, coll. Pour l'histoire, 2004 (rééd. Alinéa, 1988) 


\section{Regionalización y contrarrevolución}

El tema de la contrarrevolución se plantea con fuerza en el Coloquio de Rennes de 1985 sobre las resistencias a la Revolución. Por primera vez se defiende como posible la existencia, negada hasta entonces por la tradición republicana, de una contrarrevolución popular ${ }^{75}$. Nuevas perspectivas sobre una cuestión que no había sido apenas tocada (salvo en el mundo campesino investigado por Paul Bois, Charles Tilly o Claude Petit-Frère) desde la obra de Jacques Godechot en $1961^{76}$.

Las propuestas de Donald Sutherland ${ }^{77}$, que interpreta la revolución como una guerra civil en la que una enorme contrarrevolución popular derriba y redirige a los sucesivos gobiernos revolucionarios, alentaron también una historiografía considerada hasta entonces como reaccionaria y contraria a una identidad nacional francesa que se relacionaba estrechamente con la Revolución ${ }^{78}$. Siguiendo la línea del historiador americano, que muestra que los efectos de la revolución varían enormemente en relación con las economías regionales, las estructuras sociales y las afiliaciones religiosas, se publican diversos estudios sobre Rennes ${ }^{79}$, ciudad en la que parece haberse iniciado la Revolución de 1789, y otras localidades como Nantes, Lille, ${ }^{80}$ Fontainebleau etc. Estas investigaciones, que analizan las tensiones entre la capital y las provincias, han marcado el desplazamiento del centro de análisis de la Revolución de la capital a las regiones y provincias de Francia.

75 François Lebrun et Roger Dupuy (eds.), Les Résistences à la Révolution: actes du colloque de Rennes (1985), Rennes, 1987.

${ }^{76}$ La contre-révolution: doctrine et action, 1789-1804, Paris, Presses universitaires de France, 1961.

77 France, 1789-1815: Revolution and Counterrevolution, Oxford, U. P., 1986.

78 Sutherland destacaba a fines de siglo, cómo en una historia comparada de las revoluciones, los estudios rusos y soviéticos abordaban con mucha mayor hondura las políticas de resistencia: «Revolution and Authenticity: Reflections from France on the Russian and Soviet Experience», en Kritika: Explorations in Russian and Eurasian History, vol 1, 2000, pp. 153-160.

79 Véase Michel Denis, Rennes, berceau de la liberté. Revolution et democratie: una ville à l'avantgarde, Rennes, ouest France, 1989; o Joseph Gobry, La Terreur dans le Nord de la France, París, Mercure de France, 1991.

${ }^{80}$ Gail Bossenga, The Politics of Privilege: Old Regime and Revolution in Lille, Cambridge U.P. 1991; Alan Forrest, The Revolution in Provincial France: Aquitaine, 17891799, New York, Oxfrod U. Press., 1996. 
La historia de la contrarrevolución en el oeste francés ${ }^{81}$ ha recibido también una creciente atención que ha demostrado la complejidad de la relación revolución/contrarrevolución, el carácter autónomo del movimiento campesino y sus rasgos culturales propios. Especial impulso ha recibido el caso de la Vendée, cuya historiografía mantiene posturas radicalmente encontradas como se verá más abajo.

\section{Historiografía antirrevolucionaria}

Una corriente muy distinta de la anterior, de oposición total a la Revolución - en la que Furet dijo no reconocerse - ${ }^{82}$, vuelve al debate público de la mano de un historiador tan conocido como Pierre Chaunu. Miembro del Instituto de Francia y profesor de la Sorbona, Chaunu publica en 1989 La révolution declassée, que destroza el mito de la Revolución de 1789. La fuerza negativa de su análisis considera el Terror como la culminación de las ideas revolucionarias. Lo que le lleva a definir la política de los gobiernos en la Vendée como un genocidio ${ }^{83}$.

Desde la cátedra de la Sorbona, Chaunu dirige a un grupo de investigadores fieles a la memoria de la Vendée, la tradición maurrasiana, excomunistas como Alain Besançon y Jacques Dupâquier o liberales como Jean Tulard. ${ }^{84}$. El ejemplo más extremo de esta línea se muestra en la obra de Reynald Secher, Le Génocide franco-français: La Vendée-vengé ${ }^{85}$. El autor acusa a la república jacobina de exterminar sistemáticamente a los campesinos enemigos.

Jean Clément Martin, gran especialista en la Vendée ${ }^{86}$, contesta con contundencia estos argumentos que contravienen la ortodoxia jacobina. Niega que existiera una identidad «veendeana» anterior a la guerra de

${ }^{81}$ Roger Dupuy, Les Chouans, Hachette Littérature ,1997 y La Bretagne sous la Révolution et l'Empire, 1789-1815, éditions Ouest-France Université, Rennes, 2004.

82 Michel Vovelle, «L'Historiographie de la Révolution Française a la veille du bicentenaire», en Annales historiques de la Révolution française, 1988, 272, pp. 113-126, p. 119.

${ }^{83}$ Hugh Gough, «Genocide and the Bicentenary: The French Revolution and the Revenge of the Vendée,» Historical Journal 30 (1987), p. 978.

${ }_{84}$ Véase la polémica en Steven Kaplan, Adieu 89, París, Fayard, 1993.

85 París, P. U. F., 1986.

${ }^{86}$ Ha publicado numerosas obras sobre la Vendée, la más reciente: La Guerre de Vendée, 1793-1800, París, Points-Seuil, 2014. 
1793; considera que la guerra nace en un contexto de luchas políticas partisanas e invoca la falta de pruebas documentales o de un cuerpo de doctrina de exclusión para descartar que hubiera ejecuciones planifica$\operatorname{das}^{87}$.

En 2008 la aparición del volumen dirigido por Renaud Escande, Le Livre noir de la révolution française ${ }^{88}$, expone la parte negra de masacres y de inhumanidad que tienen como emblema el terror de la Vendèe. Frente a la larga tradición mitificadora de la Revolución, el libro de Escande - escrito por conocidos historiadores como el propio Chaunu, Emmanuel Le Roy Ladurie, Jean Tulard o Jean de Viguerie - denuncia por primera vez el inmenso coste humano de la misma y reconoce en la religión un elemento decisivo. Los autores muestran una parte de la realidad que ha sido escondida o al menos ignorada, al ofrecer un compendio desmitificador de algunos de los grandes símbolos de la Revolución. El objetivo principal del libro negro no es tanto proclamar los efectos colaterales perjudiciales de la revolución, cuanto cuestionar su significado. Esta interpretación de historiadores - miembros algunos de las Academias francesas - ha generado una respuesta de rechazo contundente por parte de otros especialistas como Mona Ozouf - miembro del Centro de investigaciones políticas de la École des hautes études en Sciences Sociales (EHESS) y directora de investigación en el Centre national de la recherche scientifique (CNRS) - o Jean-Clément Martin, director del Institut d'histoire de la Révolution française ${ }^{89}$.

\section{La revitalización de la herencia clásica}

La concentración revisionista en el discurso político de la Revolución dejó bastante de lado la cuestión de cómo la cultura política emergió en una particular coyuntura socio-económica. Desde la muerte de

87 Jean-Clément Martin, «Reynald Sécher, Vendée. Du Génocide au mémoricide. Mécanique d'un crime légal», en Annales historiques de la Révolution française, 368, 2012, pp. 194-196. Martin excluye significativamente a Secher del diccionario de la contrarrevolución (Jean-Clément Martin (dir.), Dictionnaire de la Contre-Révolution, Paris, Perrin, 2011).

${ }^{88}$ París, Éditions du Cerf, 2008.

89 Dichos historiadores han llegado a tachar la obra de manipulación integrista. Véase Trois critiques du Livre noir de la Révolution française (Jean-Clément Martin, Mona Ozouf, Pierre Assouline) en Parti de Gauche, miércoles 21 de diciembre de 2011. 
Soboul en 1982, ninguna figura destacada trató de reconstruir la interpretación clásica. En el ámbito anglosajón el libro de Henry Heller ${ }^{90}$ sobre la Revolución, publicado en 2006, constituye la primera explicación explícitamente marxista desde que el revisionismo entrara en cuestión. Heller arremete contra los historiadores revisionistas, cuya hegemonía explica en términos de influencia política. El historiador canadiense defiende una reintroducción de las tesis socioeconómicas que consideran la revolución como burguesa y capitalista, y frente a otros marxistas, como George Comninel ${ }^{91}$ - que aceptan elementos esenciales de la crítica revisionista-, subraya cómo emergen la agencia y la conciencia de clase de la burguesía a través del proceso revolucionario. Mientras Lefebvre y Soboul resaltan el papel del pueblo en la Revolución, Heller coloca el acento en el papel director de la burguesía. La obra de Heller supone un punto de arranque para la revitalización de la herencia clásica, en cuanto realiza una síntesis de la crítica anti-revisionista de las dos últimas décadas.

Especialmente tras la muerte de Furet en 1997, se inicia una nueva etapa más calmada en el mundo universitario, en la que se trata de restablecer la posición algo eclipsada del Institut d'Histoire de la Révolution Française (IHRF) y la Société des études robespierristes como centro de debate histórico de gran calado ${ }^{92}$. Los estudios revolucionarios remontan así bajo la dirección de Jean Clément Martin (2000-2008) y Pierre Serna (desde 2008). Es de destacar, que esta historiografía - que se ha denominado «neojacobina»- es sustancialmente distinta de la escuela clásica, en cuanto que incluye cultura y mentalidades y ciertos aspectos de lo político $^{93}$.

La Révolution française ${ }^{94}$ de Michel Biard y Pascal Dupuy, revisada a la luz de las investigaciones aparecidas tras el bicentenario, subraya dos aspectos principales: el carácter de ruptura política fundamen-

90 Henry Heller, The Bourgeois Revolution in France, 1789-1815, Bergahn Books, Oxford-New York, 2006.

${ }_{91}$ Rethinking the French Revolution. Marxism and the Revisionist Challenge, London, Verso Press, 1997.

92 Jean-Clément Martin (dir.), La Révolution à l'oeuvre. Perspectives actuelles dans l'histoire de la Révolution française, Rennes, Presses Universitaires de Rennes, 2005.

93 Claude Mazauric, «Aperçu des tendences et des enjeux historiographiques: le necessaire débat», en Cahiers d'histoire. Revue d' histoire critique, 94-95, 2005, pp. 19-25.

${ }_{94}$ Michel Biard et Pascal Dupuy, La Révolution française. Dynamiques, influences, débats. 1787-1804, Paris, Armand Colin, Coll. U, 2004. 
tal para la construcción de la democracia en Francia y la posición del proceso en un entorno internacional, que distingue sus respectivas singularidades e influencias. Las nuevas tendencias se observan igualmente en otra monografía dirigida también por Michel Biard: La Révolution Française, une histoire toujours vivante ${ }^{95}$. Se publica en alusión a Furet y para responder a las tesis del Libro negro de la Revolución. Pero más allá de una renovación de la herencia clásica, insiste sobre la necesidad de mantener un compromiso intelectual, "porque desde el pasado, la Revolución sigue interrogando el futuro» ${ }^{96}$. A lo largo de la obra, una treintena de historiadores exponen, cada uno en su campo, el estado actual de los conocimientos sobre la Revolución. Tras decenios de batallas ideológicas se observa una investigación más tranquila, en la que se hace una historia política renovada, en la encrucijada de lo social y cultural. De hecho, casi todas las contribuciones tocan de alguna manera lo político. Lo que demuestra que la herencia de Furet no está del todo liquidada, aunque se convierta en algo más complejo centrado en torno al concepto de politización y nacimiento de un espacio público de autonomía frente al poder ${ }^{97}$.

En 2012 se celebró el 75 aniversario del IHRF fundado por Georges Lefèvre en 1937. Ese año constituye por ello una fecha señalada con la presentación de varias monografías sobre la Revolución. También con un sentido político combativo y como reivindicación de la memoria republicana, se publicaron dos investigaciones: La dirigida por Jean-Marc Schiappa, Pour la défense de la Révolution française 1789-200998, que parte de la revolución como matriz de la democracia contemporánea y plantea las cuestiones de fondo que se confrontan en la actualidad. La segunda obra, de Jean-Luc Chappey, Bernard Gainot, Guillaume Mazeau, Frédéric Régent y Pierre Serna, es Pourquoi faire la Révolution. Aporta su visión de

95 París, Tallandier, 2010.

96 Véase esta idea más desarrollada en Révolution-Révolutions à l'horizon 2011-2012, Note de la Fondation Gabriel Péri, febrero de 2012.

97 Véase Cyril Triolaire, «La Révolution Française au miroir des recherches actuelles», en La Révolution Française au miroir des recherches actuelles, Paris, Société des études robespierristes, 2011, p. 9-11.

98 Jean-Marc Schiappa (dir.), Pour la défense de la Révolution française 1789-2009, colloque de l'Institut de Recherches et d'Études de la Libre Pensée, 2008, L'Harmattan, Paris, 2012 y Jean-Luc Chappey, Bernard Gainot, Guillaume Mazeau, Frédéric Régent, Pierre Serna, Pourquoi faire la Révolution, Comité de vigilance face aux usages publics de l'Histoire, Agone, Marseille, 2012. 
la historiografía revolucionaria desde 1989 y, al desencadenarse los nuevos procesos revolucionarios en el mundo árabe, reclama la centralidad de la Revolución francesa como laboratorio de la política. Es de destacar igualmente, el planteamiento global, que incorpora el mundo atlántico a la historia revolucionaria. Una clara muestra del cambio del IHRF en su tradicional postura euro y galocentrista ${ }^{99}$.

\section{Reconceptualización del Terror}

El Terror sigue siendo uno de los grandes temas de la Revolución. En los últimos años varias investigaciones aportan nuevas propuestas sobre una cuestión que afecta de lleno al debate actual ${ }^{100}$ y que se revela como un tema central en la búsqueda de un nuevo paradigma explicativo. Más allá de las interpretaciones revisionistas y marxistas sobre la necesidad o la contingencia, se estudia la lógica interna que conduce al Terror como parte del proceso revolucionario.

Desde la óptica revisionista, el discípulo de Furet, Patrice Guéniffey ${ }^{101}$, entiende el Terror como el desarrollo de una violencia orgánica - cambiante en las formas y mecanismos institucionales - pero consustancial a la revolución. La ideología revolucionaria - para la escuela furetiana factor determinante en el desarrollo revolucionario - es para Guéniffey un arma elaborada y desplegada por los actores revolucionarios para sus propios fines. Otros autores anglosajones, mantienen versiones distintas. Así el norteamericano Dan Edelstein ${ }^{102}$, que se apoya en una argumentación ideológica que considera el terror un medio de imponer la Ilustración y la tradición de la ley natural, o el historiador británico David Andress ${ }^{103}$ que, desde una nueva «vuelta a los acontecimientos», defiende que sobre la base de la realidad histórica del momento, se conjugaron la radicalidad ideológica y los ataques de pánico por un lado, con

99 Planteamiento que ya mostró Serna (ed.) en Républiques soeurs: le Directoire et la Révolution atlantique, Rennes, Presses universitaires de Rennes, 2009.

100 Especialmente tras los levantamientos de la primavera árabe desde 2010.

101 Patrice Gueniffey, La politique de la Terreur. Essai sur la violence révolutionnaire (1789-1794), Paris, Fayard, 2000.

102 Dan Edelstein, The Terror of Natural Right: Republicanism, the Cult of Nature, and the French Revolution, Chicago, University of Chicago Press, 2009.

103 The Terror: Civil War in the French Revolution, Little Brown, 2005. (Traducc. española, El Terror: los Años de la Guillotina, Edhasa, Barcelona, 2011) 
la fría manipulación de la venganza en la lucha por el poder. Ninguno de ellos termina de demostrar si fue la lógica del discurso, el miedo a la guerra exterior, el pánico generado por la guerra civil o los complots reales o imaginarios lo que genera el terror. ${ }^{104}$

La corriente «neojacobina» ha tratado de romper la asociación entre revolución y totalitarismo por medio de una explicación más amplia de las políticas del Terror. Michel Biard afirma que para comprender el terror hay que contemplar sus efectos más contradictorios a diferentes niveles. Para ello plantea la existencia en plural, de las políticas del Terror, que define como todos los modos posibles que se utilizan para defender la Revolución ${ }^{105}$.

La historiadora francesa e investigadora del CNRS, Sophie Wahnich, publica en 2003, La liberté ou la mort: Essai sur la Terreur et le terrorisme ${ }^{106}$. Un ensayo que desarrolla y apuntala el planteamiento historiográfico de la izquierda sobre la relación entre revolución, violencia $\mathrm{y}$ terror en general. Wahnich se adentra en el terreno de las emociones y construye un argumento sobre la furia y la agresividad popular y las drásticas medidas que toma la Convención para contenerlas. La violencia revolucionaria francesa de 1973 se justificaría según la citada autora por su base de moral y de justicia.

Aunque no prevalece ninguna visión única, la nueva historia de la violencia y, en particular el estudio de Jean Clément Martin, Violence et Révolution ${ }^{107}$ - cuyo título no menciona el terror - tienen el objetivo de deconstruir la propia noción del terror. Así, más que contestar a la cuestión de por qué se produce, plantea cuál es la naturaleza del propio fenómeno. Martin considera la revolución como un fenómeno social, pero con elementos políticos. Pretende superar los presupuestos de las dos corrientes historiográficas que se enfrentaron en el último tercio del siglo XX y aspira a plantear una visión desapasionada de la revolución. Así, si por un lado retoma los análisis sociales sobre la revuelta po-

104 Para una síntesis sobre estos debates véase Hugh Gough, The Terror in the French Revolution, Houndmills Palgrave, 2010.

105 Missionnaires de la République. Les représentants du peuple en mission (17931795), Paris, Éd. du CTHS, 2002.

106 Éditions de la Fabrique, Paris, 2003, ed inglesa: In Defence of the Terror: Liberty or Death in the French Revolution, Verso Books, London- New York, 2012.

107 Jean Clément Martin, Violence et révolution. Essai sur la naissance d'un mythe nacional, Fayard, Paris, 2006. 
pular de los jacobinos, por otro estima que esas motivaciones de clase no son sus causas fundamentales. Igualmente, Martin se separa también de la interpretación discursiva basada en el «giro lingüístico» y defendida principlamente por Keith M. Baker ${ }^{108}$. Si bien acepta algunos logros del análisis del lenguaje, como el hecho de considerar la dialéctica revolucionario/contrarrevolucionario una construcción discursiva, destaca en cambio la importancia de las relaciones sociales, fundamentalmente conflictivas, que provocaron la revolución ${ }^{109}$. La violencia, referencia omnipresente en la construcción de un mito alentado tanto por los herederos de la revolución como por sus oponentes, no sería lo esencial del proceso revolucionario, sino su dramaturgia. Además, Martin busca sus raíces en las formas de violencia utilizadas por las elites durante el Antiguo Régimen y resalta la importancia de las luchas locales que tuvieron un amplio margen de autonomía frente a la capital francesa. Esto no le induce a ignorar los episodios sangrientos de la realidad del terror, pero los entiende como resultado de una inmensa transformación y de lo que «procede de una realidad ocasional «. En su amplio argumentario, explica también el fenómeno de la violencia por la ausencia o debilidad del Estado, la rivalidad y el conflicto de intereses llevaron a una espiral de persecución irracional en la que más que la ideología, primó la necesidad de dar una respuesta urgente a cuestiones que anteriormente ni siquiera se habrían podido imaginar ${ }^{110}$.

El norteamericano Micah Alpaugh ha añadido una nueva dimensión al debate, al enmarcar la violencia revolucionaria en un contexto de protesta popular largamente ignorada y caracterizada por la no violencia. Alpaugh otorga un papel central a los sans-culottes en el desarrollo de las formas democráticas de protesta ${ }^{111}$.

108 Véase Keith Michael Baker, «El concepto de cultura política en la reciente historiografía sobre la Revolución Francesa», Ayer, n. ${ }^{\circ}$ 62, 2006, 2, pp. 89-110.

109 Jean-Clément Martin, op. cit., 2006, p. 11-12.

110 Bruno Chaouat (dir.), Penser la terreur. Actes du Colloque de Cerisy 21-31-julio de 2006, Éditions Universitaires, Dijon, 2009; Michel Biard (ed.), Les politiques de la Terreur, 1793-1794: Actes du Colloque international de Rouen, 11-13 de enero de 2007, organizado por el GRHis-Université de Rouen y la Société des études robespierristes, Rennes, 2008.

111 Micah Alpaugh, Non-Violence and the French Revolution: Political Demonstrations in Paris, 1787-1795, Cambridge University Press, 2014. 


\section{El debate sobre Robespierre}

En relación con el Terror, se observa también una vuelta de Robespie$\mathrm{rre}^{112}$ al debate historiográfico. Una figura que en las celebraciones conmemorativas del bicentenario había sido prácticamente ignorada, ya que el entonces presidente francés, François Mitterrand, quiso evitar con ello alusiones a la cara más sangrienta de la Revolución, vuelve a suscitar la polémica.

Frente a interpretaciones revisionistas como la de la historiadora británica Ruth Scurr que, en Fatal Purity: Robespierre and the French Revolution $^{113}$, denuncia los peligros de un idealismo político desbocado, Peter McPhee encuentra en Robespierre a Revolutionary Life ${ }^{114}$ una justificación de la violencia ejercida con una finalidad revolucionaria. En opinión de McPhee, Robespierre no sería tanto un revolucionario, cuanto un hombre hecho por la Revolución.

En Francia obra colectiva dirigida por Michel Biard y Philippe Bourdin, Robespierre. Portraits croisés, ${ }^{115}$ refleja el interés y la renovación de los estudios dedicados a su figura. Diecisiete especialistas tratan de desmontar la leyenda negra sobre el Incorruptible. Las posturas son variadas y algunos autores resaltan también las contradicciones y los fracasos de Robespierre. Por ejemplo, Guillaume Mazeau subraya cómo el revolucionario alienta con sus discursos un clima de guerra civil. La polémica y las incógnitas que, ya desde la Revolución, ha suscitado el político jacobino mantienen pues viva la falta de consenso en torno a su figura.

En un reciente artículo, «The Overthrow of Maximilen Robespierre and the "Indifference" of the People» ${ }^{116}$, el británico Colin Jones abre nuevas pespectivas de investigación. El autor demuestra que la población parisina - frente a las tesis en curso que suponían la indiferencia política- apoyó activamente a la Convención Nacional contra Robespie-

112 Marc Belissa y Julien Louvrier, «Robespierre dans les publications françaises et anglophones depuis l'an 2000», en Annales historiques de la Révolution française, 371, 2013, pp. 73-93.

113 Henry Holt and Company, New York, 2006.

114 Yale University Press, New Haven, 2007. Traducido al español: Robespierre. Una vida revolucionaria, Barcelona, Península, 2012.

115 Paris, Armand Colin, 2013.

116 En American Historical Review, 2014, 119, 3, pp. 689-713. 
rre. El hecho de que el movimiento popular parisino apoyase la legalidad constitucional mucho más fervientemente de lo que se suponía, plantea para Jones la necesidad de reevaluar el carácter de la política popular en el conjunto de la Revolución.

\section{Conclusión}

La Revolución francesa continúa siendo la cuestión más debatida y controvertida de toda la historia de Francia. Tras el eclipse de los dos modelos marxista y revisionista como explicación totalizante de la Revolución, la historiografía ha tratado de avanzar, en las dos últimas décadas del siglo Xx y primeras del siglo actual, en la búsqueda de nuevas vías de abordar su enorme complejidad. Al compás que marca la evolución de la ciencia histórica desde los años 70, se analiza la revolución desde diversos ángulos y giros historiográficos: la historia intelectual y cultural, las prácticas de los actores, sus sentimientos y emociones, el giro social, la historia colonial y el giro global. Sin embargo, ninguna de estas corrientes ha acertado a resolver todas las aporías que plantea la relación entre las estructuras económico-sociales y las acciones y experiencias de los sujetos. Aunque nuevas ideas han renovado prácticamente cada subespecialidad en el campo de las investigaciones revolucionarias, sigue con todo sin encontrarse ninguna teoría explicativa sobre la Revolución en su conjunto, sus orígenes y sus causas. La fragmentación del campo de estudio que se observa, al menos desde fines de siglo, ha convertido a la Revolución en un lugar de interacciones complejas y, en ocasiones, contradictorias. Y es que cuanto más se ha investigado, más difícil es integrar ese conocimiento en las categorías y teorías existentes. La falta de una interpretación dominante se observa en casi todos los grandes temas de la Revolución. Una situación que refleja la propia realidad histórica del momento actual caracterizada por el policentrismo y la pluralidad. Pero la ausencia de un paradigma explicativo o la toma de posturas políticas contrapuestas no impiden la aparición de nuevas y prometedoras propuestas de análisis.

En el panorama reciente de la investigación se presentan como tendencias de fondo: una nueva historia social que restituye, frente a las categorías tradicionales, las experiencias y contingencias vividas por los actores; En segundo lugar, la globalización de la Revolución, integrando la interacción entre el impacto exterior y la historia colonial y el correspon- 
diente efecto sobre el ámbito interno de Francia. En tercer lugar, una revitalización de la herencia clásica, que reivindica el papel central de la revolución en la creación del republicanismo y la democracia moderna, así como una reconceptualización del terror. El determinismo ideológico y el galocentrismo quedan así apartados.

La historiografía sobre la Revolución se encuentra, sin duda, en una etapa de prometedora renovación, en la que se precisan estudios empíricos más detallados para responder a las interesantes cuestiones que plantean las nuevas re-conceptualizaciones.

En síntesis, un intenso desarrollo de la investigación histórica que ha proyectado nuevas luces para el análisis, pero que -lejos de conclusiones totalizantes - aporta una argumentación menos pretenciosa sobre el significado de la Revolución - privilegiado laboratorio de análisis - que, al fin y al cabo, continúa siendo un enigma. 